\title{
Editorial
}

\section{Climate change as a unifying theme in Antarctic research}

$\mathrm{H}$ ow many times have you seen statements similar to the following: "Antarctica is a global barometer", "Antarctica is a warning beacon for global change", or "Antarctica is the most sensitive continent to climate change"? The frequency of such statements in this, and other polar journals, is significant. We know that the polar regions are highly sensitive to natural and human induced changes that originate elsewhere on our planet, and the literature is extensive and growing. At the large scale there is increasing evidence of both direct and indirect linkages between climate patterns (e.g. ENSO) in the Pacific and Atlantic oceans and Antarctic climate. At a smaller scale are the follow-on linkages to glacier dynamics, including surface melt, glacier stream flows, lake levels, beaches, sea-ice dynamics and ice tongues. All of these have major repercussions on Antarctic ecosystems. The phase change from water (liquid) to ice (solid) occurs over a very small temperature range (depending on salinity, pressure etc). Thus, for a pond ecosystem, a change in temperature of less than one degree Celsius means the difference between a functioning aquatic ecosystem, and a frozen ecosystem. The recent IPCC report (Climate Change 2001 [3 vols], Cambridge University Press) leaves little doubt of the significant changes to world climate now taking place. As Antarctic scientists we surely must therefore consider that the principal issue to be addressed in Antarctica at present is that of "Responses to a changing climate". Several national programmes (Australian, British, New Zealand to name a few) have already signalled in their future plans that this theme will be a major focus. A feature of science carried out in many national programmes is that of small individual projects driven mostly by the interests of Principal Investigators, with limited continuity and a lack of comparative data between projects. Whilst we should always have resources to support bright new ideas is there also now a compelling case for a more thematic focus? Antarctica offers the international science community the opportunity of combining resources and intellectual ability to address a single issue of global importance. It is the only continent where this can occur. If "Responses to a Changing Climate" was a key theme in every national programme and endorsed by international bodies such as SCAR (or even SCOR), we would begin to see cohesion in the type of research carried out as well as international and multidisciplinary research which has morecomparable data sets and approaches. Surely this combined expertise and focus would rapidly achieve results? SCAR currently endorses an ecological programme known as RiSCC ((Regional Sensitivity to Climate Change). This is a start, and I believe we need to progress this now. Some interesting ways of thinking about this are the so-called "Latitudinal Gradient" or "Latitudinal Transect" approaches, which treat latitudinal changes to climate as a surrogate for climate change. This is conveniently done in the polar regions where the latitudinal effects are more pronounced than in temperate and tropical regions. For instance, the difference in mean annual temperature along the coast between Cape Adare $\left(70^{\circ} \mathrm{S}\right)$ and the Beardmore Glacier $\left(84^{\circ} \mathrm{S}\right)$ is $4^{\circ} \mathrm{C}$. Differences in ecosystem structure and processes between these sites may be a key to climate change effects in similar ecosystems in the future. There are many other ways of addressing the issue of responses to a changing climate and there will be very significant advantages in a co-ordinated approach. Can this be the first major science challenge for a re-organised SCAR?

Clive Howard-Williams 